\title{
Evaluation of extraction methods for arsenic speciation in polluted soil and rotten ore by HPLC-HG-AFS analysis
}

\author{
Chun-Gang Yuan ${ }^{1,2}$, Bin He ${ }^{1}$, Er-Le Gao ${ }^{1}$, Jian-Xia Lü ${ }^{1}$, and Gui-Bin Jiang ${ }^{1, *}$ \\ 1 State Key Laboratory of Environmental Chemistry and Ecotoxicology, Research Center for Eco-Environmental Sciences, \\ Chinese Academy of Sciences, P.O. Box 2871, 100085 Beijing, P.R. China \\ 2 School of Environmental Science and Engineering, North China Electric Power University, Baoding 071003, Hebei, P.R. China
}

Received September 6, 2006; accepted November 1, 2006; published online February 23, 2007

(C) Springer-Verlag 2007

\begin{abstract}
Three extraction systems including shaking, ultrasonic and microwave-assisted extraction were evaluated. Water and phosphate buffer were tested for the extraction of arsenic compounds in polluted soil, describing the water-soluble or plant-available fraction. The stabilities and recoveries of various arsenic species indicated that no obvious changes of species occurred during the extraction process. The raw extracts were cleaned up by $\mathrm{C}_{18}$ cartridge before analysis. Having optimized the extraction conditions, the arsenic species in polluted soil and ore from the different pollution sources were extracted by microwave-assisted extraction with $0.5 \mathrm{M}$ phosphate buffer as extractant. Arsenic species were quantitatively determined by high performance liquid chromatography on-line coupled with hydride generation atomic fluorescence spectrometry (HPLC-HGAFS). As(III) and As(V) were the major arsenic species in the polluted soil samples resulting from irrigation by waste water. $\mathrm{As}^{\mathrm{V}}$ was the only form found in the rotten ore sampled in mining area. During the extraction process, the recoveries of spiked As(III), As(V), DMA(V) and MMA(V) were $85.4 \pm 7.2 \%, 80.2 \pm 6.7 \%, 101.6 \pm$ $6.7 \%$ and $98.8 \pm 9.1 \%$, respectively, showing that most water-soluble arsenic could be measured.
\end{abstract}

\footnotetext{
* Author for correspondence. E-mail: gbjiang@rcees.ac.cn
}

Key words: Arsenic speciation; microwave-assisted extraction; soil and ore.

Arsenic species can transform and translate in the environment during their circulation processes [1] and the total content of arsenic is not adequate for risk assessment of arsenic pollution. The toxicity of arsenic is dependent on its form and oxidation state that occurs in the environment [2]. Arsenic resulting from the using of pesticides or pollution in soil can be transferred into vegetables, cereal, and other food and accumulated through food chain [1], which can pose risks to human in the end. Soil and atmospheric suspended particles ingestion can also be another important way of exposure to arsenic [3, 4]. Arsenic speciation analysis in soil can help us to understand the biochemical process of arsenic from soil to plants and to assess the public health risk [5-7].

The contents of arsenic in soil varied dramatically according to different regions. Normally, in non-contaminated soils the arsenic contents are in the range of $1-40 \mu \mathrm{g} \mathrm{g}^{-1}$, but the concentration of arsenic higher than $20 \mathrm{mg} \mathrm{g}^{-1}$ could be measured in some old industrial or mining sites [8]. This high concentration of arsenic can be dissolved and transformed under different environmental conditions. However, not all of the arsenic presented in polluted soil or mining area 
can pose an immediate environmental risk because of their low water solubility. The water soluble or plant available arsenic in soil was more critical for environment, because this part of arsenic will be easier to be absorbed by plants grown on the field [9]. The determination of water soluble or plant available arsenic species in polluted soil is very important for understanding the uptake, transfer and accumulation processes of arsenic in plants.

Some online coupling systems of chromatographic separation with the specific element detection techniques are robust for arsenic speciation analysis [2]. To achieve the high sensitivity and selectivity, inductively coupled plasma-mass spectrometry (ICPMS) has been used as the detector of coupling system for arsenic speciation. However, high price and expensive running cost make it unavailable for some laboratories. Hydride generation atomic fluorescence spectrometry (HG-AFS) can act as an alternative to ICP-MS with high sensitivity and selectivity for arsenic detection. By using hydride generation technique, the analytes can react into gas phase and separated from the matrix. There is little interference during the arsenic detection procedure using HG-AFS $[10,11]$. In addition, HG-AFS is always with the benefits of much lower running costs, price and easy handling.

Arsenic speciation analysis is one of the hot topics in analytical field and many researches were carried out to develop the new analysis methods in recent years [12-20]. Even the analytical methods for arsenic speciation are effective and robust, a lack of investigations still exists in the handling of solid samples prior to analysis [21], especially for the soil or other geological samples, like rotten ore. To analyze the arsenic species, the arsenic had to be extracted from the solid samples in the original forms by mild extractants. It is very important to maintain the chemical integrity of the original species. In recent years, many researches about the preparation of solid samples for arsenic speciation were carried out [4, 9, 21-39]. However, most studies were focused on plants and marine materials $[21-25,27-30,32,34,36-38]$. The research about soil is still relatively lacking $[9,31,35$, 39 ] and the considerable improvements in sample preparation techniques are still needed in arsenic speciation research area [40]. The microwave-assisted extraction was one new technology for the handing of solid samples for arsenic speciation [22, 23]. The arsenic compounds in oyster, fish tissue and other marine macroalgae could be extracted effectively by microwave-assisted extraction without obvious changing of arsenic species during the extraction process [22-24, 30, 36]. Microwave-assisted extraction had also been applied to extract the arsenic compounds in plant materials successfully $[34,37]$. Gallardo et al. [41], Montperrus et al. [31] and Ruiz-Chancho et al. [39] reported that microwave-assisted extraction was also an effective and promising method for arsenic speciation analysis in soil, sediment and sludge. Arsenic concentrations and species distribution in soils can be affected by the nature of the parent rock, organic and inorganic components, redox potential status, climate and human activities [3, 31, 35]. So it is still useful to evaluate the feasibilities of different extraction systems together for more real soil samples from various polluted areas.

In this present work, three extraction methods including shaking, ultrasonic and microwave-assisted extraction were evaluated and compared to extract arsenicals from polluted soil. The stabilities and the recoveries of different arsenic species were also tested. After optimization, arsenic species in the heavily polluted soils (about $100 \mu \mathrm{gg}^{-1} \mathrm{As}$ ) and the rotten ore (about $1500 \mu \mathrm{gg}^{-1}$ As) were extracted by microwave-assisted extraction and determined by HPLCHG-AFS.

\section{Experimental}

\section{Standards and reagents}

Arsenic stock solution $\left(1 \mathrm{mg} \mathrm{mL}^{-1}\right.$ as As) was prepared by dissolving arsenic trioxide (Johnson Metthey Chemical, Royston, Hertfordshine, UK) in $50 \mathrm{~mL} \mathrm{NaOH}\left(0.5 \mathrm{~mol} \mathrm{~L}^{-1}\right)$ solution followed by the addition of $3 \mathrm{~mL}$ concentrated $\mathrm{HCl}$ and diluted to $100 \mathrm{~mL}$ with de-ionized water. Aqueous standard stock solutions of arsenate, $\mathrm{MMA}^{\mathrm{V}}$ and $\mathrm{DMA}^{\mathrm{V}}$ were prepared by dissolving appropriate amounts of sodium arsenate (Beijing Chemical Factory, Beijing, China), monomethylarsenic acid and dimethylarsenic acid (Sigma Chemical Company, USA) in de-ionized water, respectively. Phosphate solutions used as extractants were prepared from sodium phosphate (Beijing Chemical Factory, Beijing, China). All chemicals were of analytical grade or better. In the chromatographic separation the mobile phase used as a gradient between $100 \mathrm{mmol} \mathrm{L}^{-1}$ and $10 \mathrm{mmol} \mathrm{L}^{-1} \mathrm{NaOH}$. The mobile phase was prepared by dissolving sodium hydroxide (Beijing Chemical Factory, Beijing, China) in deionized water and filtrated through a $0.22 \mu \mathrm{m}$ porosity membrane filter and degassed before use. The methanol and hexane (HPLC grade) used in this experiment were purchased from Dikma Technology Inc., USA. The ethanol (GR grade) was from Beijing Chemical Factory, Beijing, China. C18 carteidges were from Varian Technologies, China. De-ionized water produced by the compact ultrapure water system, EASYpure LF (Barnstead Co., USA), $18 \mathrm{M} \Omega$-cm, was used for the preparation of reagents and standards. 


\section{Instrumentation}

Liquid chromatography

A quaternary pump (P680 HPLC Pump, Dionex, USA) equipped with a Rheodyne Model 7725 i injector valve (Rheodyne, Cotati, CA, USA) and a $20 \mu \mathrm{L}$ sample loop was used. An anion-exchange column (IonPac AS11, Dionex, USA) equipped with a guard column (IonPac AG11, Dionex, USA) was used to separate arsenic species. The program of mobile phase used in the chromatographic separation procedure was a gradient between $100 \mathrm{mmol} \mathrm{L}^{-1}$ and $10 \mathrm{mmol} \mathrm{L}^{-1} \mathrm{NaOH}$ with the flow rate as $1 \mathrm{~mL} \mathrm{~min}^{-1}$.

\section{Hydride generation}

A peristaltic pump was applied to pump $\mathrm{HCl}$ solution and $\mathrm{KBH}_{4}$ solution. The effluent from the column was carried by $10 \% \mathrm{HCl}$ solution and mixed and reacted with $3 \% \mathrm{KBH}_{4}$ solution in T-cross valve. Then the gas-liquid mixture was separated in the gas-liquid separator. After being separated by the second gas-liquid separator the analytes in gas phase was carried into the atomizer and detected by AFS. The column, T-cross valve and the gas-liquid separator were connected by PTFE tube.

\section{Atomic fluorescence detection}

The analytes were introduced into the atomizer warmed by infrared radiation and atomized by argon-hydrogen flame. Determinations were performed by an AF-610A atomic fluorescence spectrophotometer (Beijing Ruili Analytical Instrument Co., Beijing, China) at $193.7 \mathrm{~nm}$ line source with a hollow cathode lamp operating at $270 \mathrm{~V}$ of PMT voltage and $60 \mathrm{~mA}$ primary lamp current and $30 \mathrm{~mA}$ assistant lamp current. A personal computer fitted with the software of AFS610 was required for the control of the AFS and the integration of the peak areas.

\section{Samples}

The polluted soil and rotten ore samples were collected from Hunan Province, P.R. China. Some areas in Hunan province are suffering arsenic or other heavy metals pollution because of the arsenic mines and waste water irrigation. Sample S1 was the rotten ore collected around arsenic mine in Shimen area; Samples S2 and S3 were from farmland irrigated with waste water for a long period in Chenzhou area. Several kilograms soil was collected into the plastic bags and was mixed entirely. After being freeze-dried, the samples were grinded in a mortar and sieved with 100 mesh screen for use.

\section{Extraction procedure}

\section{Microwave-assisted extraction}

A microwave accelerated reaction system (Mars5 HP500, CEM corporation, USA) was applied for the microwave-assisted extraction in the experiment. Three $1.0 \mathrm{~g}$ parallel soil samples were weighted into the PTFE tubes and $20 \mathrm{~mL}$ extract reagent (deionized water or phosphate buffer) was filled in the tube. The PTFE tubes were capped and placed into the microwave system. The program of the microwave system for extraction was as follow: increase the temperature from room temperature to $95^{\circ} \mathrm{C}$ in $10 \mathrm{~min}$, keep for $15 \mathrm{~min}$ and then cool down to room temperature in $10 \mathrm{~min}$. After each extraction program, the supernatant was removed after centrifugation and $5 \mathrm{~mL}$ water was added to the residue. For each case, the later extraction procedure was repeated two times and the extractants were combined and made up to $50 \mathrm{~mL}$. A blank was made in the same way at the same time.

\section{Shaking extraction procedure}

One gram of polluted soil sample was filled in a $50 \mathrm{~mL}$ glass centrifuge tube and then $20 \mathrm{~mL}$ extract regent (deionized water or phosphate buffer) was added. The tubes were put onto the horizontal rotator shaker and shaken for $12 \mathrm{~h}$ with the open end capped by parafilm. After centrifugation at $3500 \mathrm{rpm}$ for $15 \mathrm{~min}$, the suspension was removed with pipette, then another $5 \mathrm{~mL}$ solvent was added to the residue and the tubes were shaken for $2 \mathrm{~h}$. This procedure was repeated two times and the extractants were combined and made up to $50 \mathrm{~mL}$. A blank was made at the same time.

Ultrasonic extraction procedure

Each sample set contained three replicate samples and a blank. A $1.0 \mathrm{~g}$ soil sample was extracted with $20 \mathrm{~mL}$ of extractant. Each extraction required vortex mixing, $1 \mathrm{~h}$ for sonication and $15 \mathrm{~min}$ of centrifugation at $3500 \mathrm{rpm}$. The supernatant was removed into a PTFE bottle and the procedure was repeated with $5 \mathrm{~mL}$ reagent for two times. Finally, the supernatants were combined and made up to $50 \mathrm{~mL}$.

All the glass containers used in the experiment were leached in 1:1 $\left(\mathrm{HNO}_{3}: \mathrm{H}_{2} \mathrm{O}\right)$ nitric acid and rinsed with distilled water. The extracts from the samples were stored in PTFE tubes at $4{ }^{\circ} \mathrm{C}$ in refrigerator before analysis.

\section{Total digestion}

The three batches of freeze-dried samples $(0.1 \mathrm{~g})$ were weighted into a $30 \mathrm{~mL}$ Teflon container with seal and then $1.0 \mathrm{~mL}$ concentrated $\mathrm{HNO}_{3}, 0.5 \mathrm{~mL} \mathrm{HClO}_{4}$ and $0.5 \mathrm{~mL}$ hydrofluoric acid were added in sequence. The container was heated at $180^{\circ} \mathrm{C}$ for $6 \mathrm{~h}$. The digestion solution was diluted to $10 \mathrm{~mL}$ with de-ionized water for analysis. The standard reference material ${ }^{\circledR} 2711$ (Montana soil) was used to control the digestion process and to evaluate the recovery of arsenic. The certified value of arsenic was $105 \pm 8 \mu \mathrm{g} \mathrm{g}^{-1}$. The measured value in this experiment was $98.5 \pm 6 \mu \mathrm{g} \mathrm{g}^{-1}$. The recovery was $93.8 \%$.

\section{Results and discussion}

\section{Quantitative analysis of arsenic species by HPLC-HG-AFS}

The online coupling system (Fig. 1) was applied to analyze the arsenic species in the extracts obtained from different extraction methods and the experimental conditions for HPLC-HG-AFS were shown in Table 1. The arsenic species in the sample extracts were separated using an anion-exchange column (IonPac AS11, Dionex, USA), which was eluted at $1 \mathrm{~mL} \min ^{-1}$ with the sodium hydroxide solution (gradient, $100-10 \mathrm{mML}^{-1}$ ) as mobile phase. The eluate from the HPLC system was continuously introduced into HG-AFS instrument. $20 \mu \mathrm{L}$ of sample was injected 


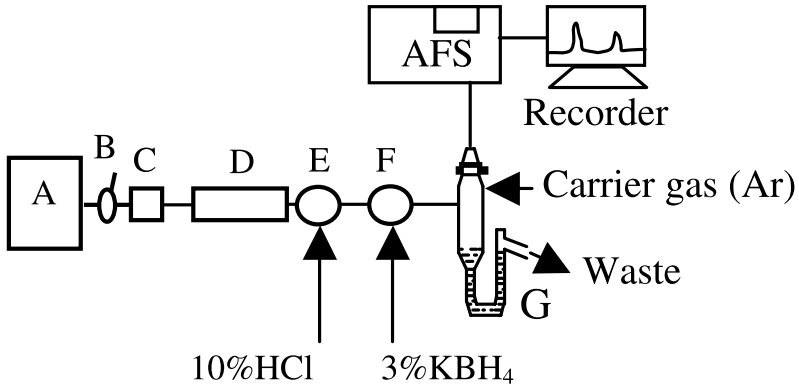

Fig. 1. Schematic diagram of HPLC-HG-AFS. A LC pump; $B$ Injector; $C$ Guard column; $D$ Separation column; $E$ and $F$ Connection; $G$ Gas-liquid separator

Table 1. Experiment conditions for HPLC-HG-AFS

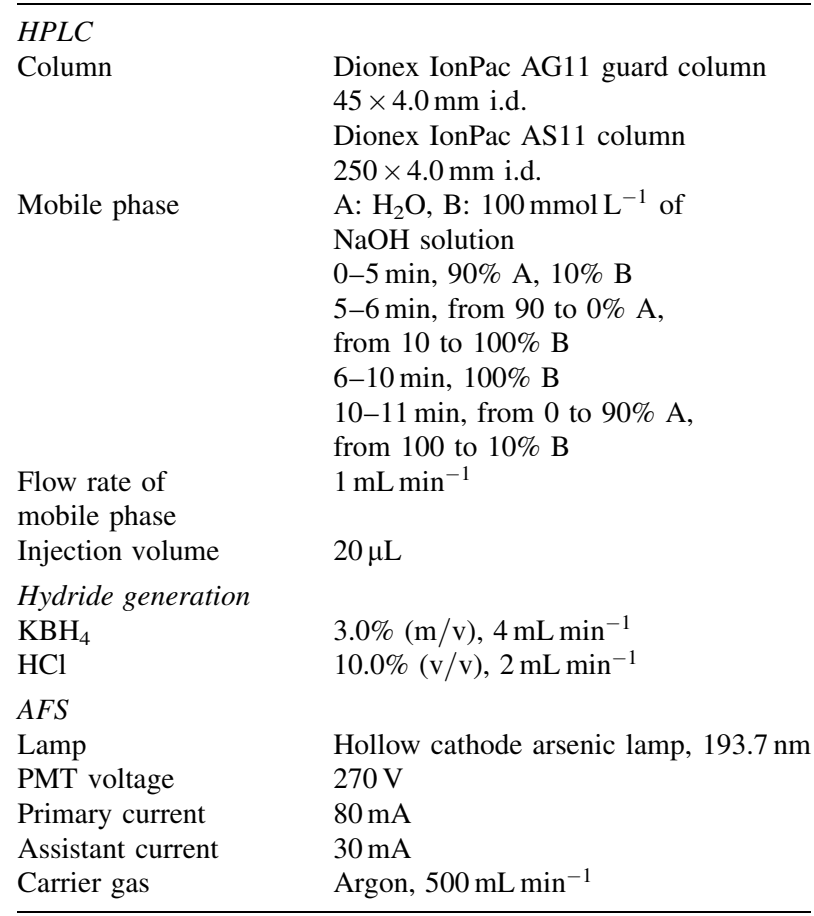

and the chromatographic peaks were recorded. The arsenic compounds were identified by their retention times as indicated in Fig. 2. The intensity of each chromatographic peak area was quantified against corresponding calibration curves constructed by injection of standard mixtures of known concentrations into the HPLC-HG-AFS. By using the hydride generation technique, the matrix effects and interferences were minimized. Detection limits, defined as the concentration of analyte that produces a chromatographic peak having a height equal to three times the standard deviation of the baseline noise [42]. The detection limits for $\mathrm{As}^{\mathrm{III}}, \mathrm{As}^{\mathrm{V}}, \mathrm{DMA}^{\mathrm{V}}$ and $\mathrm{MMA}^{\mathrm{V}}$ were $2.76,5.22,7.37$ and $2.86 \mathrm{ng} \mathrm{mL}^{-1}$, respectively.

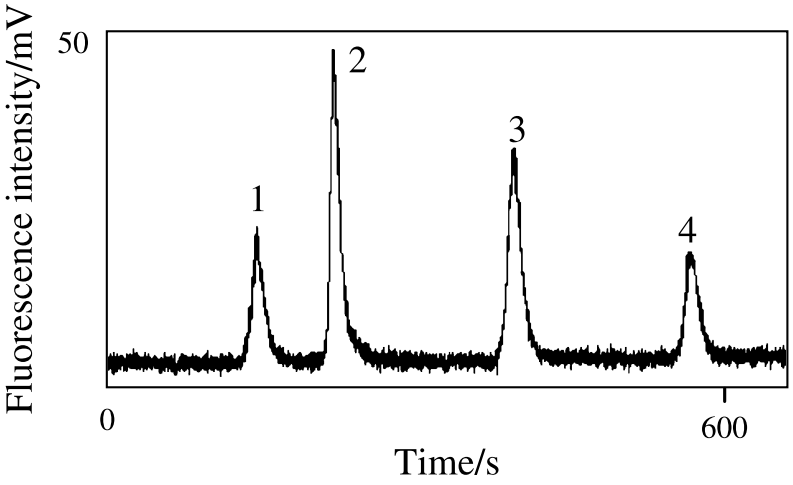

Fig. 2. Chromatogram for the mixed standard solution. Standard solution $25 \mathrm{ng} \mathrm{mL}^{-1}$ for $\mathrm{As}^{\mathrm{III}}, \mathrm{As}^{\mathrm{V}}, \mathrm{MMA}^{\mathrm{V}}$ and $\mathrm{DMA}^{\mathrm{V}}$, respectively. $1 \mathrm{DMA}^{\mathrm{V}} ; 2 \mathrm{As}^{\mathrm{III}} ; 3 \mathrm{MMA}^{\mathrm{V}} ; 4 \mathrm{As}^{\mathrm{V}}$

\section{Stability of the arsenic species during the extraction process}

To be sure the arsenic species will not be changed obviously during the extraction process, the mixed standards solution of the four arsenic forms ( $\mathrm{As}^{\mathrm{III}}$, $\mathrm{As}^{\mathrm{V}}, \mathrm{MMA}^{\mathrm{V}}$ and $\mathrm{DMA}^{\mathrm{V}}$ at $100 \mathrm{ng} \mathrm{mL}^{-1}$, respectively) was spiked into the extractants without samples and was submitted to the extraction procedure. Finally, the spiked standards were analyzed by HPLC-HG-AFS in the same way as the samples to verify their stabilities during the extraction procedure.

In this experiment, distilled water and phosphate solution $(500 \mathrm{mM})$ were used as extraction solvents and three different extraction procedures, shaking, ultrasonic and microwave-assisted extraction, were used. The recoveries for the four arsenic species during the different extraction methods were showed in Table 2. The four arsenic species could be quantitatively recovered almost $100 \%$ when ultrasonic, shaking and microwave were applied, no matter water or phosphate solution $(500 \mathrm{mM})$ was used as extractant. The results indicated that the procedure of extraction would not make significant changes of the arsenic forms.

\section{Recoveries of different arsenic species}

In order to investigate the extraction efficiency of arsenic species during the extraction process, different arsenic species were spiked into the real soil samples to make the final spiked standards of $\mathrm{As}^{\mathrm{III}}, \mathrm{As}^{\mathrm{V}}, \mathrm{DMA}^{\mathrm{V}}$ and $\mathrm{MMA}^{\mathrm{V}}$ at $20 \mu \mathrm{g} \mathrm{g}^{-1}$, respectively. After dried by air at room temperature and mixed, the spiked samples were submitted to the extraction procedures. The recoveries were calculated by compared the measured value which had been deducted the original content 
Table 2. Stability of arsenic species using different extraction methods $(\%, n=3)$

\begin{tabular}{|c|c|c|c|c|c|}
\hline Method & Extractant & $\mathrm{As}^{\mathrm{III}}$ & $\mathrm{DMA}^{\mathrm{V}}$ & $\mathrm{MMA}^{\mathrm{V}}$ & $\mathrm{As}^{\mathrm{V}}$ \\
\hline Ultrasonic & distilled water & $98.1 \pm 6.2$ & $90.1 \pm 5.4$ & $96.4 \pm 7.1$ & $107.8 \pm 4.9$ \\
\hline Ultrasonic & phosphate solution $^{\mathrm{a}}$ & $101.2 \pm 3.7$ & $89.5 \pm 2.5$ & $90.4 \pm 2.1$ & $99.8 \pm 5.0$ \\
\hline Shaking & distilled water & $99.2 \pm 6.1$ & $85.8 \pm 3.1$ & $95.2 \pm 6.7$ & $96.0 \pm 3.5$ \\
\hline Shaking & phosphate solution $^{a}$ & $95.8 \pm 3.2$ & $86.6 \pm 3.9$ & $102.5 \pm 7.9$ & $99.0 \pm 5.1$ \\
\hline Microwave & distilled water & $98.4 \pm 4.7$ & $90.8 \pm 6.2$ & $95.2 \pm 6.3$ & $112.1 \pm 6.3$ \\
\hline Microwave & phosphate solution $^{\mathrm{a}}$ & $100.3 \pm 6.1$ & $89.2 \pm 4.0$ & $98.5 \pm 4.7$ & $96.7 \pm 7.1$ \\
\hline
\end{tabular}

${ }^{\text {a }}$ Phosphate solution: $500 \mathrm{mM}$.

Table 3. Recoveries of the arsenic species spiked in soil samples $(\%, n=3)$

\begin{tabular}{|c|c|c|c|c|c|}
\hline Method & Extractant & $\mathrm{As}^{\mathrm{III}}$ & $\mathrm{As}^{\mathrm{V}}$ & $\mathrm{MMA}^{\mathrm{V}}$ & $\mathrm{DMA}^{\mathrm{V}}$ \\
\hline Ultrasonic & distilled water & $25.1 \pm 3.8$ & $19.4 \pm 3.2$ & $37.1 \pm 4.1$ & $95.9 \pm 11.3$ \\
\hline Ultrasonic & phosphate solution $^{\mathrm{a}}$ & $67.8 \pm 9.2$ & $35.9 \pm 5.1$ & $91.7 \pm 12.7$ & $115.7 \pm 14.4$ \\
\hline Shaking & distilled water & $17.3 \pm 3.1$ & $12.3 \pm 2.8$ & $29.7 \pm 4.0$ & $92.3 \pm 9.8$ \\
\hline Shaking & phosphate solution $^{\mathrm{a}}$ & $56.8 \pm 7.5$ & $45.1 \pm 7.7$ & $85.2 \pm 10.8$ & $89.1 \pm 7.3$ \\
\hline Microwave & distilled water & $10.4 \pm 1.1$ & $20.1 \pm 2.6$ & $23.6 \pm 2.5$ & $99.0 \pm 7.8$ \\
\hline Microwave & phosphate solution $^{\mathrm{a}}$ & $85.4 \pm 7.2$ & $80.2 \pm 6.7$ & $98.8 \pm 9.1$ & $101.6 \pm 6.7$ \\
\hline
\end{tabular}

${ }^{\mathrm{a}}$ Phosphate solution: $500 \mathrm{mM}$.

of arsenic in the sample with the spiked value. The results in Table 3 indicated that the recoveries for arsenic species were distinctly different between various extraction methods with different extractants. In general, the recoveries of organic arsenic species were always better than that of inorganic species in soil samples. It could be explained that the organic species had less affinity with soil than inorganic species and easier to be extracted by the solvent. On the contrary, the inorganic species in this experiment seemed more difficult to be removed from the absorption site in soil with low recoveries. This phenomenon was especially described by the $12.3 \%$ recovery of arsenate ions when they were extracted by shaking with water. When the phosphate solution was applied, the recoveries of As ${ }^{\mathrm{III}}$, $\mathrm{As}^{\mathrm{V}}$ and $\mathrm{MMA}^{\mathrm{V}}$ became better obviously, especially for $\mathrm{MMA}^{\mathrm{V}}$. That means phosphate ions can remove the arsenic species more effective than water. It can be interpreted by that phosphate ions with strong charges can exchange the arsenic ions absorbed on the site in soil more quickly and more effectively. There was no significant difference between the recoveries for $\mathrm{DMA}^{\mathrm{V}}$ when water or phosphate was used. By shaking or ultrasonic, even when the phosphate solution was used as extractant the recoveries for As ${ }^{\text {III }}$ and $\mathrm{As}^{\mathrm{V}}$ were low (67.8 and 45.1\%). However, when the microwave assisted extraction was applied with phosphate solution as extractant the recoveries for different arsenic species would become satisfactory. 85.4 and $80.2 \%$ of total spiked could be recovered for $\mathrm{As}^{\mathrm{III}}$ and $\mathrm{As} \mathrm{v}^{\mathrm{V}}$. Although such recoveries were not
$100 \%$, they had been improved obviously and were adequate for arsenic speciation analysis in soil samples.

\section{Ion-strength effects on the extraction efficiency of the microwave assisted extraction}

The various concentrations of the phosphate solutions from 0 to $1.0 \mathrm{M}$ were used to extract arsenic in the soil samples and the extraction efficiencies were evaluated in the experiment. The results were shown in Fig. 3. From the results it could be concluded that the extraction efficiency increased with the concentration of the phosphate solution from 0 to $500 \mathrm{mM}$. When the phosphate solution was $500 \mathrm{mM}$, the ion strength of the solution was strong enough for the extraction of arsenic from the soil. However, even larger concentra-

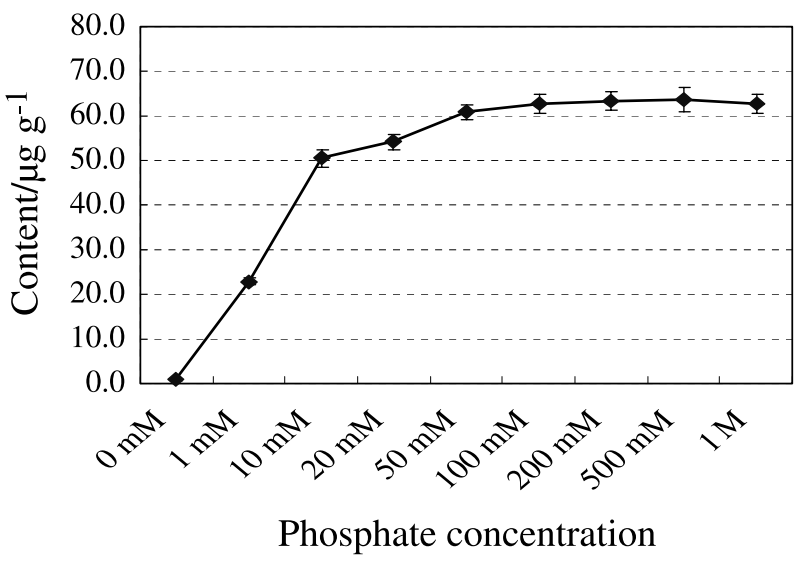

Fig. 3. Ion-strength effects on the extraction efficiency 


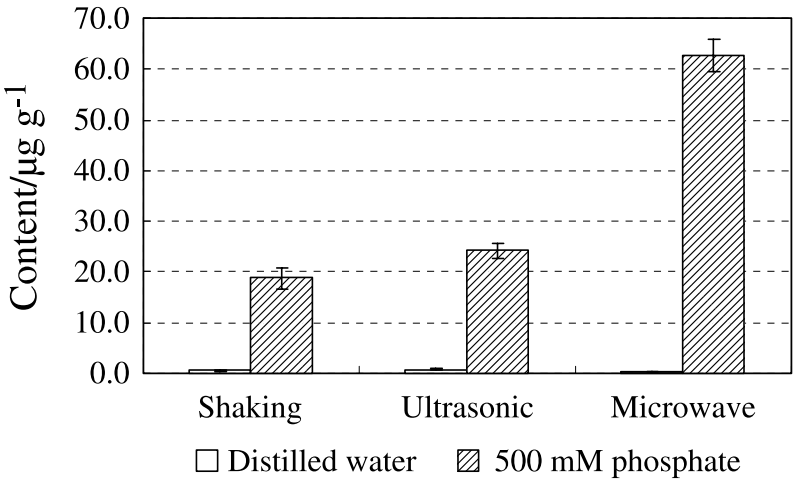

Fig. 4. Effects of different extraction methods on the extraction efficiencies

tion applied, the extraction efficiency was not improved anymore. In this experiment, $500 \mathrm{mM}$ phosphate was applied during the whole procedure.

\section{Comparison of extraction procedures by shaking, ultrasonic and microwave-assisted}

Different extraction methods, shaking, ultrasonic and microwave-assisted extraction, were evaluated and compared. Distilled water and phosphate buffer were used during the extraction process. Figure 4 showed that when $500 \mathrm{mM}$ phosphate solution was used as extractant, the extraction was more effective compared with distilled water. When distilled water was used, only $0.78,0.51$ and $0.41 \mu \mathrm{g} \mathrm{g}^{-1}$ arsenic can be extracted from the polluted soil sample for shaking, ultrasonic and microwave-assisted extraction, respectively. But when the phosphate solution $(500 \mathrm{mM})$ was used, $18.74,28.13$ and $62.26 \mu \mathrm{g} \mathrm{g}^{-1}$ of arsenic could be extracted from the sample, which had been improved by 24.0, 55.2 and 151.9 times, respectively. The different methods (shaking, ultrasonic or microwave) did not affect the extraction efficiency obviously when distilled water was used. It could be explained by that it would need more time to extract arsenic from soil by water. However, when the phosphate solution was used the extraction efficiencies for the different methods were different largely. The results indicated that arsenic in the polluted soil could be extracted effectively by microwave assisted extraction with the phosphate solution as the extraction solvent.

\section{Clean-up procedures of raw extracts}

The organic matter and other components in soil samples can pose interferences and the loss of resolution
Table 4. Stability of the arsenic species during the clean-up procedures $(\%, n=3)$

\begin{tabular}{llll}
\hline Recoveries & Active carbon & $\mathrm{C}_{18}$ cartridge & Normal hexane \\
\hline $\mathrm{As}^{\mathrm{V}}$ & $\mathrm{ND}$ & $95.5 \pm 2.8$ & $82.6 \pm 6.0$ \\
$\mathrm{As}^{\mathrm{III}}$ & $\mathrm{ND}$ & $99.1 \pm 2.6$ & $92.1 \pm 1.6$ \\
$\mathrm{MMA}^{\mathrm{V}}$ & $10.2 \pm 4.1$ & $96.7 \pm 4.9$ & $67.2 \pm 5.3$ \\
$\mathrm{DMA}^{\mathrm{V}}$ & $96.5 \pm 1.7$ & $89.8 \pm 4.1$ & $80.4 \pm 6.1$ \\
\hline
\end{tabular}

of the chromatographic separation and moreover cause damage to the chromatographic column. In order to eliminate the interferences and protect the separation column, it's better to clean up the raw extract just before analysis by HPLC. In this paper, we tried three different clean-up procedures including $\mathrm{C}_{18}$, activated carbon and hexane to choose the best one for soil extract.

To make sure that there was no obvious loss during the extraction procedure, the recoveries of different arsenic species during different clean-up procedures were evaluated. Table 4 showed the recoveries of the four species by different clean-up procedures including $\mathrm{C}_{18}$ cartridge, active carbon and normal hexane. The result indicated that the hydrophobic matters and big organic molecule could be removed from the extractant by $\mathrm{C}_{18}$ cartridge. The recoveries of $\mathrm{As}^{\mathrm{III}}, \mathrm{As}^{\mathrm{V}}$, $\mathrm{MMA}^{\mathrm{V}}$ and $\mathrm{DMA}^{\mathrm{V}}$ were 99.1, 95.5, 96.7 and 89.8\%, respectively during the clean-up procedure by $\mathrm{C}_{18}$ cartridge. The recoveries of four species were nearly $100 \%$ excepted for $\mathrm{DMA}^{\mathrm{V}}$. This result indicated that only some of $\mathrm{DMA}^{\mathrm{V}}$ compounds could be retained by $\mathrm{C}_{18}$ cartridge and the other arsenic species did not. This result was in agreement with that reported by other authors [28]. However, the recovery of $89.8 \%$ for $\mathrm{DMA}^{\mathrm{V}}$ was good enough for quantitative calculations of arsenic in soil samples. In our work, we chose $\mathrm{C}_{18}$ cartridge to clean up the raw extracts from the soil samples.

\section{Sample analysis}

The different arsenic species in the samples were analyzed by HPLC-HG-AFS system after microwave assisted extraction. The results were listed in Table 5. From the results, it can be concluded that the forms of arsenic in the soil samples were inorganic arsenic. It can be seen that only arsenate was detected in the rotten ore sample S1. For the soil polluted by irrigation with the arsenic contaminated water, a small part of arsenite was found. 
Table 5. Results of arsenic speciation analysis in the soil and rotten ore samples $\left(\mu \mathrm{g} \mathrm{g}^{-1}, n=3\right)$

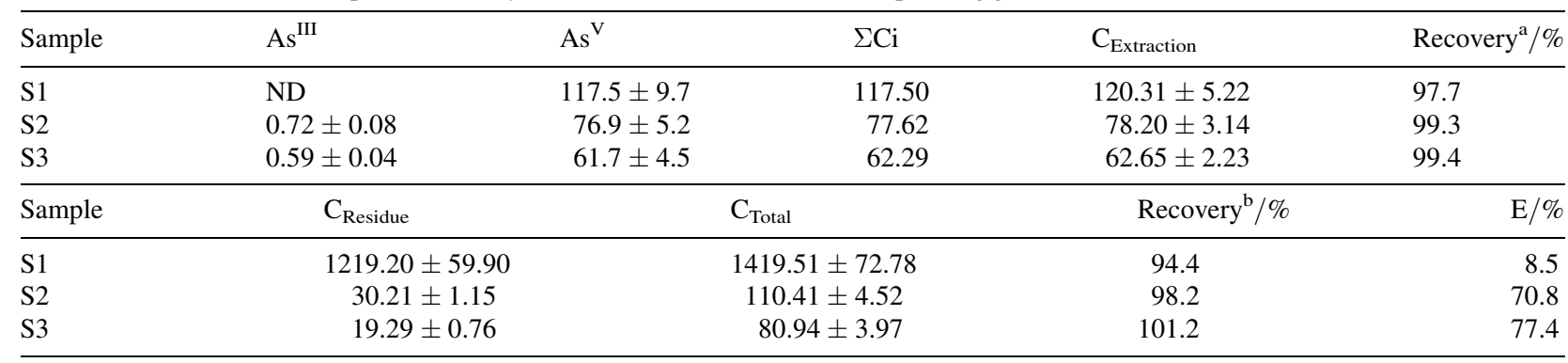

Recovery $^{\mathrm{a}}: \mathrm{\Sigma Ci} / \mathrm{C}_{\text {Extraction }}$; Recovery ${ }^{\mathrm{b}}:\left(\mathrm{C}_{\text {Extraction }}+\mathrm{C}_{\text {Residue }}\right) / \mathrm{C}_{\text {Total }} ; \mathrm{E}: \mathrm{C}_{\text {Extraction }} / \mathrm{C}_{\text {Total }}$.

The total arsenic contents in various portions including original samples, extracts and residues after extraction were also investigated by total digestion and AFS. The sum of arsenic species in the extractant was in good agreement with the total arsenic in extractant. It indicated that the arsenic in the extractant could be detected quantitatively and that no arsenic forms were missed obviously during the speciation analysis procedure. The sum of the arsenic content in the extractant and the residue were matchable with the arsenic content from the total digestion of the soil sample. It indicated that there was no significant loss during the whole analysis procedure including extraction and analysis. The extraction efficiencies for the three samples were different according to the components of the soil samples. Only $8.5 \%$ extraction efficiency was obtained for $\mathrm{S} 1$ sample. Such low extraction efficiency resulted from that $\mathrm{S} 1$ was collected from the area close to the mine and it contained rock. On the other hand, the low extraction efficiency also indicated that the arsenic in sample S1 was very hard to be absorbed by organisms. S2 and S3 were from farmland and the extraction efficiencies for them were much higher (up to 70.8 and $77.4 \%$ of the total contents). The results meant that the arsenic in the soil samples from farmland was always easier to be extracted or sucked by other organisms.

\section{Conclusions}

Compared with other methods, arsenic in the polluted soil can be extracted effectively by microwave assisted extraction procedure with phosphate solution as extractant.

The species detected in the samples were different according to the different components, the origin, and the matrix. For sample S1, which was collected near the arsenic mine, only arsenate was determined and no other forms were found. However, for sample S2 and
S3, which were polluted by the arsenic waste water irrigation, arsenite and arsenate were found.

It can be concluded that even if the same extraction procedure is applied, the extraction efficiencies for the soil samples were different according to the different components and matrix. The very low extraction efficiency was obtained for the rotten ore samples. The low extraction efficiency meant the percentage of soluble arsenic in the sample was very low. The arsenic in the soil irrigated by waste water from farmland was always easier to be extracted or sucked by other organisms.

Acknowledgements. This work was co-funded by the National Basic Research Program of China (2003CB415001) and National Natural Science Foundation (20477053). The authors thank Dr. Wen-Ju Liu for sampling the soil samples.

\section{References}

[1] Castlehouse H, Smith C, Raab A, Deacon C, Meharg A A, Feldmann J (2003) Biotransformation and accumulation of arsenic in soil amended with seaweed. Environ Sci Technol 37: 951

[2] Gong Z, Lu X, Ma M, Cullen W R, Le X C (2002) Arsenic speciation analysis. Talanta 58: 77

[3] Rodriguez R R, Basta N T, Casteel S W, Armstrong F P, Ward D C (2003) Chemical extraction methods to assess bioavailable arsenic in soil and solid media. J Environ Qual 32: 876

[4] Oliveira V, Gómez-Ariza J L, Sánchez-Rodas D (2005) Extraction procedures for chemical speciation of arsenic in atmospheric total suspended particles. Anal Bioanal Chem 382: 335

[5] Quaghebeur M, Rengel Z (2005) Arsenic speciation governs arsenic uptake and transport in terrestrial plants. Microchim Acta 151: 141

[6] Schmidt A C, Mattusch J, Wennrich R (2005) Distribution of arsenic species in different leaf fractions - an evaluation of the biochemical deposition of arsenic in plant cells. Microchim Acta 151: 167

[7] Daus B, Wennrich R, Morgenstern P, Weiß H, Palmieri H E L, Nalini H A, Leonel L V, Monteiro R P G, Moreira R M (2005) Arsenic speciation in plant samples from the iron quadrangle, minas gerais, brazil. Microchim Acta 151: 175

[8] Morita M, Edmonds J S (1992) Determination of arsenic species in environmental and biological samples. Pure Appl Chem 64: 575 
[9] Száková J, Tlustoš P, Goessler W, Pavlíkova D, Balík J, Schlagenhaufen C (2005) Comparison of mild extraction procedures for determination of plant-available arsenic compounds in soil. Anal Bioanal Chem 382: 142

[10] Le X C, Ma M (1998) Short-column liquid chromatography with hydride generation atomic fluorescence detection for the speciation of arsenic. Anal Chem 70: 1926

[11] He B, Jiang G, Xu X (2000) Arsenic specication based on ionexchange high-performance liquid chromatography hyphenated with hydride generation atomic fluorescence and on-line UV photo oxidation. Fresenius' J Anal Chem 368: 803

[12] Mattusch J, Wennrich R (2005) Novel analytical methodologies for the determination of arsenic and other metalloid species in solids, liquids and gases. Microchim Acta 151: 137

[13] Raab A, Fecher P, Feldmann J (2005) Determination of arsenic in algae - results of an interlaboratory trial: determination of arsenic species in the water-soluble fraction. Microchim Acta 151: 153

[14] Manning B (2005) Arsenic speciation in As(III)- and As(V)treated soil using XANES spectroscopy. Microchim Acta 151: 181

[15] Frau F, Rossi A, Ardau C, Biddau R, Pelo S D, Atzei D, Licheri C, Cannas C, Capitani G C (2005) Determination of arsenic speciation in complex environmental samples by the combined use of TEM and XPS. Microchim Acta 151: 189

[16] Bombach G, Klemm W, Greif A (2005) An analytical method for the separation and determination of $\mathrm{As}(\mathrm{III})$ and $\mathrm{As}(\mathrm{V})$ in seepage and acid mine drainage water. Microchim Acta 151: 203

[17] Prest J E, Baldock S J, Fielden P R, Goddard N J, Brown B J T (2005) Inorganic arsenic and selenium determination using miniaturised isotachophoresis. Microchim Acta 151: 223

[18] Font R, Vélez D, Río-Celestino M D, Haro-Bailón A D, Montoro R (2005) Screening inorganic arsenic in rice by visible and near-infrared spectroscopy. Microchim Acta 151: 231

[19] Kohlmeyer U, Jakubik S, Kuballa J, Jantzen E (2005) Determination of arsenic species in fish oil after acid digestion. Microchim Acta 151: 249

[20] Todorov T I, Ejnik J W, Mullick F G, Centeno J A (2005) Arsenic speciation in urine and blood reference materials. Microchim Acta 151: 263

[21] Schmidt A C, Reisser W, Mattusch J, Popp P, Wennrich R (2000) Evaluation of extraction procedures for the ion chromatographic determination of arsenic species in plant materials. J Chromatogr A 889: 83

[22] Ackley K L, B'Hymer C, Sutton K L, Caruso J A (1999) Speciation of arsenic in fish tissue using microwave-assisted extraction followed by HPLC-ICP-MS. J Anal At Spectrom 14: 845

[23] Chatterjee A (2000) Determination of total cationic and total anionic arsenic species in oyster tissue using microwaveassisted extraction followed by HPLC-ICP-MS. Talanta 51: 303

[24] Vilanó M, Rubio R (2001) Determination of arsenic species in oyster tissue by microwave-assisted extraction and liquid chromatography-atomic fluorescence detection. Appl Organometal Chem 15: 658

[25] Kuehnelt D, Irgolict K J, Goessler W (2001) Comparison of three methods for the extraction of arsenic compounds from the NRCC standard reference material DORM-2 and the brown alga Hijiki fuziforme. Appl Organometal Chem 15: 445

[26] Pardo-Martínez M, Viñas P, Fisher A, Hill S J (2001) Comparison of enzymatic extraction procedures for use with directly coupled high performance liquid chromatography- inductively coupled plasma mass spectrometry for the speciation of arsenic in baby foods. Anal Chim Acta 441: 29

[27] Caruso J A, Heitkemper D T, B'Hymer C (2001) An evaluation of extraction techniques for arsenic species from freeze-dried apple samples. Analyst 126: 136

[28] Vela N P, Heitkemper D T, Stewart K R (2001) Arsenic extraction and speciation in carrots using accelerated solvent extraction, liquid chromatography and plasma mass spectrometry. Analyst 126: 1011

[29] He B, Fang Y, Jiang G, Ni Z (2002) Optimization of the extraction for the determination of arsenic species in plant materials by high-performance liquid chromatography coupled with hydride generation atomic fluorescence spectrometry. Spectrochim Acta Part B 57: 1705

[30] Tukai R, Maher W A, McNaught I J, Ellwood M J (2002) Measurement of arsenic species in marine macroalgae by microwave-assisted extraction and high performance liquid chromatography-inductively coupled plasma mass spectrometry. Anal Chim Acta 457: 173

[31] Montperrus M, Bohari Y, Bueno M, Astruc A, Astruc M (2002) Comparison of extraction procedures for arsenic speciation in environmental solid reference materials by high-performance liquid chromatography-hydride generation-atomic fluorescence spectroscopy. Appl Organometal Chem 16: 347

[32] Pizarro I, Gómez M, Cámara C, Palacios M A (2003) Arsenic speciation in environmental and biological samples: extraction and stability studies. Anal Chim Acta 495: 85

[33] Milstein L S, Essader A, Murrell C, Pellizzari E D, Fernando R A, Raymer J H, Akinbo O (2003) Sample preparation, extraction efficiency, and determination of six arsenic species present in food composites. J Agric Food Chem 51: 4180

[34] Quaghebeur M, Rengel Z, Smirk M (2003) Arsenic speciation in terrestrial plant material using microwave-assisted extraction, ion chromatography and inductively coupled plasma mass spectrometry. J Anal At Spectrom 18: 128

[35] Kahakachchi C, Uden P C, Tyson J F (2004) Extraction of arsenic species from spiked soils and standard reference materials. Analyst 129: 714

[36] Karthikeyan S, Hirata S, Iyer C S P (2004) Determination of arsenic species by microwave-assisted extraction followed by ion-pair chromatography-ICPMS: analysis of reference materials and fish tissues. Intern J Environ Anal Chem 84: 573

[37] Yuan C, Jiang G, He B (2005) Evaluation of the extraction methods for arsenic speciation in rice straw, Oryza sativa L., and analysis by HPLC-HG-AFS. J Anal At Spectrom 20: 103

[38] Száková J, Tlustoš P, Goessler W, Pavlíkova D, Balík J (2005) Comparison of mild extraction procedures for determination of arsenic compounds in different parts of pepper plants (Capsicum annum L.). Appl Organometal Chem 19: 308

[39] Ruiz-Chancho M J, Sabé R, López-Sanchez J F, Rubio R, Thomas P (2005) New approaches to the extraction of arsenic species from soils. Microchim Acta 151: 241

[40] Francesconi K A (2003) Working methods: complete extraction of arsenic species: a worthwhile goal? Appl Organometal Chem 17: 682

[41] Gallardo M V, Bohari Y, Astruc A, Potin-Gautier M, Astruc M (2001) Speciation analysis of arsenic in environmental solids Reference Materials by high-performance liquid chromatography-hydride generation-atomic fluorescence spectrometry following orthophosphoric acid extraction. Anal Chim Acta 441: 257

[42] ACS Committee on Environmental Improvement (1980) Guidelines for data acquisition and data quality evaluation in environmental chemistry. Anal Chem 52: 2242 